The International Journal of Multimedia \& Its Applications (IJMA) Vol.6, No.3, June 2014

\title{
THE INFLUENCE OF EYES AND BRAIN BEHIND "ARTERMA TOOL" IN FIRST PERSON POINT OF VIEW INTERFACE OF GAMES
}

\author{
Irma Shayana Samaden ${ }^{1}$, Azizah Jaafar ${ }^{2}$ and Irza Shayani Samaden ${ }^{3}$ \\ ${ }^{1}$ Department of Multimedia,Faculty of Informatics and Computer, \\ Universiti Sultan Zainal Abidin,Kuala Terengganu, Malaysia \\ ${ }^{2}$ Science and Information Technology Department, Faculty of Technology and \\ Information Science Universiti Kebangsaan Malaysia Bangi, Selangor \\ ${ }^{3}$ Faculty of Medicine, National Medical University O.O Bogomolets Kyiv, Ukraine
}

\begin{abstract}
The application of point of view (POV) in electronic games has been vastly applied and fast becoming a favorite among electronic games (EG) players particularly in games of action genre like warfare games. While allowing the users to experience the character first-hand, POV has its limitations for users. One example of the problems is the difficulty to anticipate the direction an attack by the enemy from a POV blindspot. Another problem is the difficulty to prepare a strategy. Some players become "somewhat dizzy" and eventually give up the game. This paper elaborates on the development of a framework for interactive montage on EG software interface using ArTerma tools and how the ArTerma tool works in the POV interface. Therefore, to accomplish the development of ArTerma tools, (AI(DDI)2E3) model is used. In (A1(DDI)2E3) model usage, ADDIE model is combined with other model concept such as "DiegesisSpatiality" concept Model, Frame concept model, and Mental concept model has been employed along side an elaboration on case studies. The study hopes that the developed a new model as well as support tool can help improve future EGs.
\end{abstract}

\section{KEYWORDS}

Point of View, electronic games, interface POV, brain and eyes biology

\section{INTRODUCTION}

Today electronik games (EG) is a popular game, because with EG players can hang out, increasing the number of connections and it is one of the medium relieved the pressure This, EG can be classified into two parts, that is "game in" and "game out" of line. [4] However today, the environment has change as well as increasing demand from EG players has led into the development of the many genre. Such as: 1) Adventure, 2) Action 3) Role Playing 4) Strategy 5) Simulation 6) Sports 7) Match 8) Casual 9) Puzzle 10) Education 11) In-line and 12) of God.

EG must connected with interface, it because the players have interacted with interface has player base on there scenario or the genre. EG interface is divided into two categories which are: i)

DOI : 10.5121/ijma.2014.6302 
The International Journal of Multimedia \& Its Applications (IJMA) Vol.6, No.3, June 2014

physical interface and ii) internal interface [19]. Physical interface is a device used as a contributor and a way for the participants to communicate with computers. Among a few examples of physical interface that act as a situation controller in an EG are: joystick, keyboard, and mouse. Where as the internal interface for an EG covers menu buttons and POV. Every POV is capable of giving the experience impact, space, and different impact in browsing and exploring the EG.

Interface is a physical mediator for an EG and is the gateway for players to explore the game. EG Interface can be categorised into two: i) Physical Interface and ii) Internal Interface. Physical interface is a tool used as connector and means of communication between the computer and the player. Examples of physical interface acting as situational control tool in an EG are: joystick, keyboard dan mouse [19]. Meanwhile, the internal interface of EG, includes a few menu buttons and viewpoints. Every viewpoint can produce different experience, space and impression impacts in experiencing the game.Viewpoints are closely related to EG. [20]. Players will fully communicate with the game environment especially the environments in the EG using multiple viewpoints. Among the favourite viewponts among EG players: (i) First-person (POV), (ii) Third-person, (iii) Third-person Trailing, Overhead Or Top-Down (generally known as God Point of View) and (iv) Three-Four Isometric viewpoint. In POV, players need to think creatively and quickly in strategising their movements. Every movements needs to be in line with the storyline or the genre of the EG [19].

This research was conducted to develop a tool in the form of an interactive montage and to integrate the ArTerma tools technique in the developed POV interface to overcome the problems associated with it while retaining the view of POV in the EG [20;5;6. Thus, POV EG enthusiasts can play the game with minimal problems. Furthermore, this EG that the study intends to develop features the local scenery backgrounds, local background musics as well as local characters. It is also the intention of this research to promote local contents to the world while proving that this project is locally made. For warfare genre EG players, they can also learn war tactics applied by the Malaysian Armed Forces in combating the communists. Lastly, the study is unique in its model development. The ID model can be a guideline to other multimedia researchers so that the developed multimedia softwares are much more systematic and well organized by applying the approaches outlined in theories as well as the characteristics in software development.

\section{LITERATURE REVIEW}

Based on the review of existing literatures, the study found that while there has been a vast quantity of researches on the internal interface with POV view but they are mostly focused on character development on the interface. Most of these researches seek to develop characters with decision making capabilities akin to a human or characters with Artificial Intelligence (AI). Besides, the suitable tools for this type of view is still not fully developed, requiring extra tools to be connected to the console, resulting in loss of interest among game players on POV games. Physical interfaces like: i) Keyboard, ii) Mouse and iii) Joystick has significantly transformed [20] in line with technological developments. Nonetheless, for internal interface like the POV, the liteartures indicate that none of the physical interfaces are retained for for POV games. Most of them suggest additional character in the game or additional tools to be connected to the existing ones. This can eliminate the use of POV which is very popular among EG players $[16 ; 8$; $5 ; 11 ; 6 ; 3]$. 
The International Journal of Multimedia \& Its Applications (IJMA) Vol.6, No.3, June 2014

\section{HOW ArTerma WORKS}

ArTerma shows and involves 3 parts of tools. They are: i. Character information - Includes name, picture, numbers, strength, advantage, rank, location and time. ii. Surrounding information - Includes landscape information, enemies' location and traps locations and iii. Player information - Such as the power, tools, weapons and life span.

This is shown in (Figure $1-2)$ :

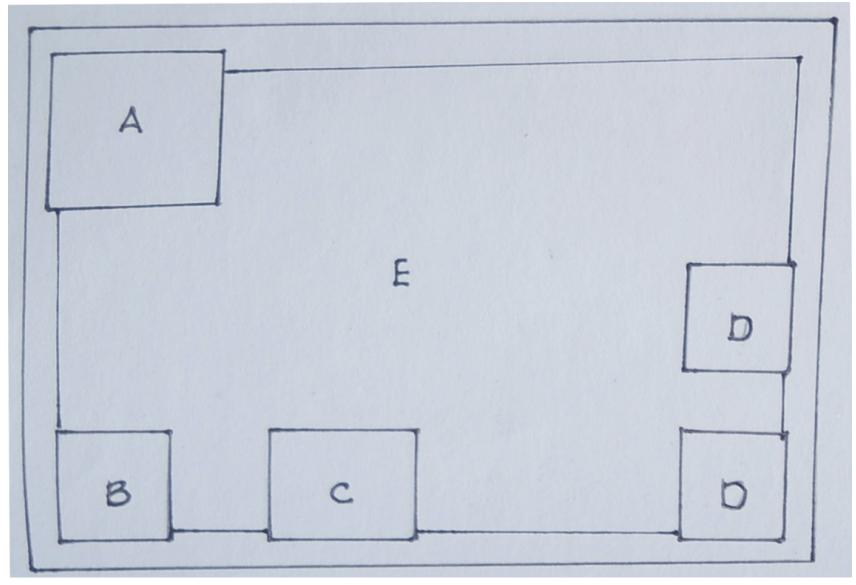

Figure1. Interface developed by researcher

Keys:

A - Mini map, B - Lifespan, C - Player information, D - Weapons information, E - EG interface
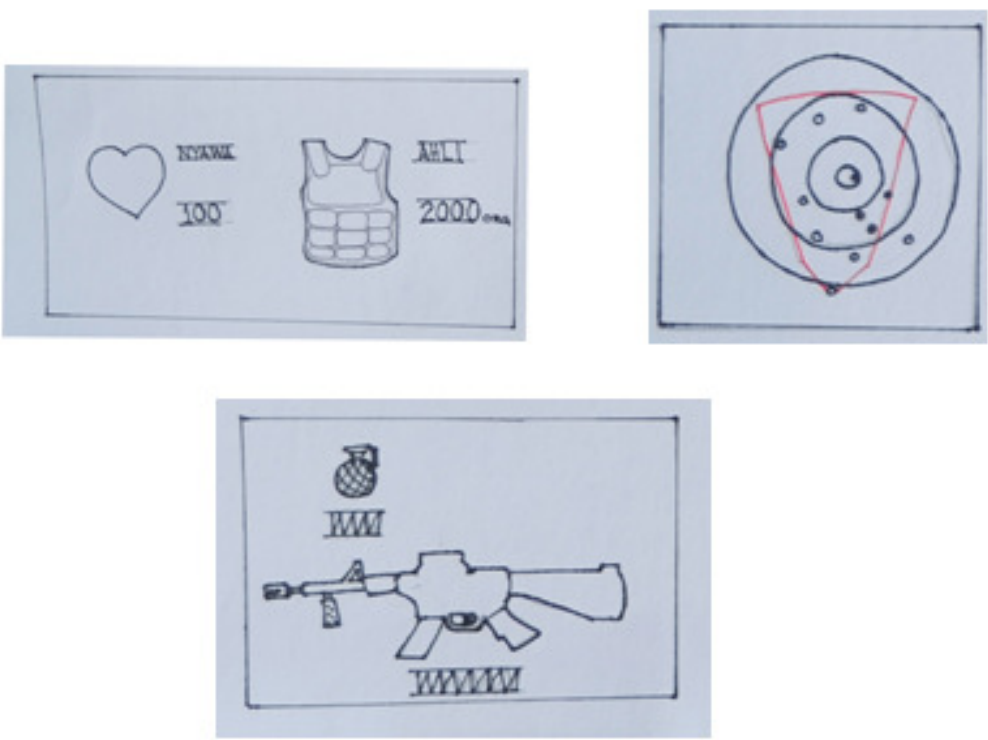

Figure 2. Character, surrounding and weapons information 
The International Journal of Multimedia \& Its Applications (IJMA) Vol.6, No.3, June 2014

Besides that, there other component that should be highlight in creating the trailer ArTerma tool. First, mostly this interface design text written in Times New Roman or Arial form. This because this form of text is more flexible, firm and more appropriate with war genre game. Secondly, overall designers use dark background or "low key" color because usually those wars took place before dawn, around 12 am and above. While the location more focus in the jungle. By using dark background, player could experience the war situation more than usual.

Designers focus more to human-like figure character in ArTerma tool trailer development for graphic and animation element. However for audio and background sound, lively background audio (using local music as local rock band 'Search') will allow gamers feel more suspend, 'heart-beating' situation and experience the war feeling which is the focus of this trailer.

Therefore, while framework of this interface been done, formative evaluation process also been done at the same time to get any feedback from users. From the questionnaire done, every opinion from gamers been analyzed and improvement will be done to upgrade and solve the problems in POV interface. While for animation development, composition software and supportive software selection process had been done earlier. In trailer development realization, researchers choose 3D Studio Max software as composition software. This composition software can prepare framework which can integrate some multimedia elements. The evaluation process done again to check the fluency level in development process.

ArTerma tools can be realized with the supported by eye and brain. Therefore, as (figure 3) shows how the role played by the eyes and brain a the interface using ArTerma tools been described:

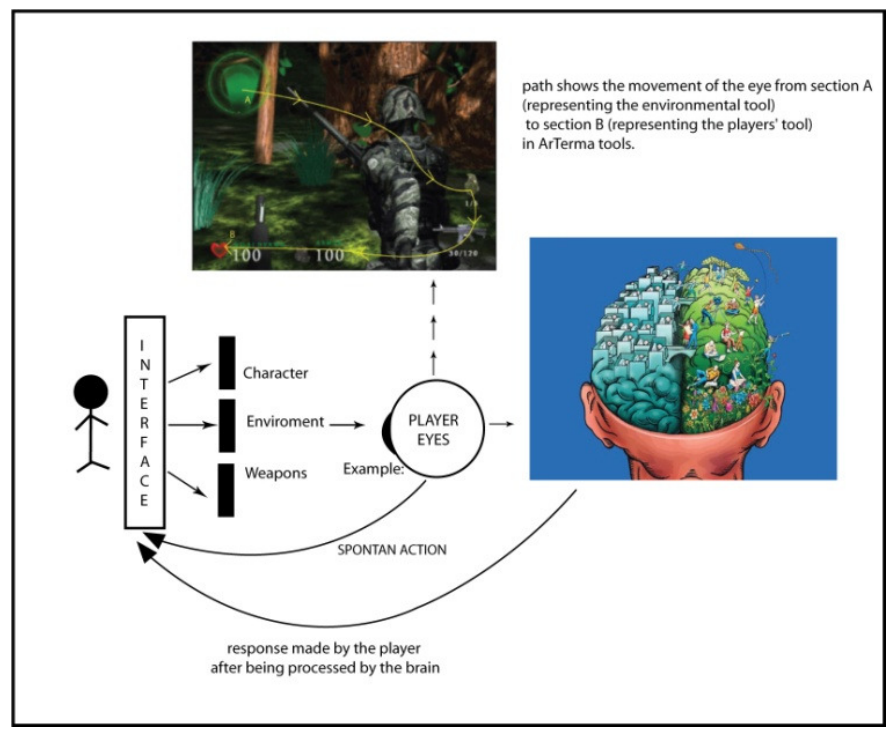

Figure 3. Movement reaction which happened to gamers who use ArTerma interface

In references [18] and [12] did a short list of whole picture of why eyes movement is important while creating interface in their research. There is an opinion stated that: Eyes are something that fast. Simple and manage to collects information thru high speed broadband. Eyes movement shows speed and really sharp. Every good framework will stress on eyes movement or eyes flow. 
The International Journal of Multimedia \& Its Applications (IJMA) Vol.6, No.3, June 2014

Elements that will give pressure on eye visual during collecting information are related to, i. eyes position (iris), ii. element that attract the visual contrast. iii. Clear eye sight iv. Uniformly to avoid confuse v. Using of horizontal and vertical grids to locate the elements and vi. Avoid using too many different sizes to avoid eye tired. There is no specific exercise for eyes because eyes can search the important object naturally. In other words, there is a relation between brain system and 'control display'. Eyes are good medium in giving first impression. Usually eyes will look at something interesting, beautiful or attractive than other organ (eg. Hands, brain etc) will take further actions. The more eyes need to move in one field of view, meant less info will be received and kept before process in brain [18].

Each person has a potential called 'natural dominant', natural dominant help brain to react automatically. There is a situation where people will use their hands or legs automatically. In Ned Herrmann, President of the Brain Institute, research noted that when gamer play games using POV interface, gamer will find that she/he (refer to character in mini map on the ArTerma) under attack, automatically player will protect themselves without logical thinking or follow the turns before counter attack the enemies by command their hand to shoot the enemies.

Brain takes part in every movement or action that made by other part of body. This is influence by some factors like life experience and education. It's shown by the way of thinking and acting. For example, if gamers find out that they ran out of bullets and surrounded by enemies (this information is shown by ArTerma), player will find the way to get more bullets, so that gamers can protect their selves and team members while accomplish their mission.

According to the information given (ran out of bullets and surrounded by enemies), brain will bring information from past to alert player before they ran out of bullets and further action can be plan. To be comparison if the gamers didn't use ArTerma in the game interface, gamer will be surprise when they suddenly realized that they already ran out of bullets and at that time any further strategy plan will be useless.

Researchers like to focus EG in war strategy game because [6] (see figure 4) divided brain into 4 parts.

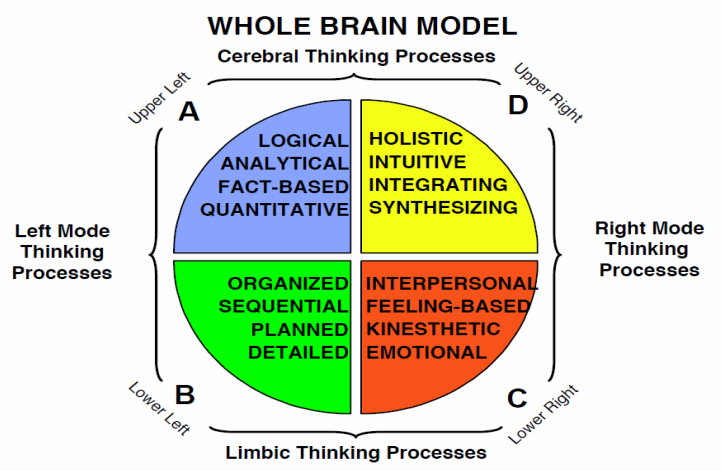

Figure 4. Quadrant model of brain by Herrmann, N. 1995

Each part included language, value and different way of processing, there: 
The International Journal of Multimedia \& Its Applications (IJMA) Vol.6, No.3, June 2014

i. Quadrant A: external studies - learning from lectures, textbook etc.

ii. Quadrant B: code by means studies - follow the test, step by step what been taught, a lots of practice to make it perfect.

iii. Quadrant C: interactive studies - discussion, experiment and oral motivations.

iv. Quadrant D: internal studies - learn from pictures, aim, understanding concept, holistic and intuition.

The way of thinking and learning style are important factor in learning management and also in teaching. People more into visual type learning will learn faster by looking at pictures or diagrams compare with listen to the lectures. The way of thinking can form perception to understand surrounding better and more productive. Brain as knowledge generator and research center and then the brain has a great function in every living thing which is found by Imam Ghazali, 900 years ago. He suggest and point out 5 brain functions [1]. He point out that there are some brain activities such as memory, visualization and shadow, emotional, synthesis, and thinking abilities. Dr. Hussein Nabil Hasyim, Surgeon from Iskandariah University said that brain is the main function of physical body. Brain is used for thinking, planned and control human living activities and functions. Brain system is one of unique system. This can be seen in the human response (behavior, reaction and action) done in achieving their objectives. This response can be classified into: i. Organization response - conscious response and ii. Unconscious response - reflex action (social action is not included).

This concept study relation between surrounding and physiology activity in human brain. Therefore, this response involves in communication process on one issue and cognitive theory usage as shone on frame model. In this research where the object oriented program and metaphor works dependently, brain model concept is used as a base. Either of these programs is used to solve the problems in creating an interface which based on consumers. Metaphor is used on something that related to simple and can be found on daily life. Object oriented program used to runs application system using metaphor. This technique will accelerate the understanding process and efficiency of human thought. Concept of usability evaluation (easy to use) of an interface prototype was developed to evaluate the software to examine how users of the prototype. Besides that, this evaluation also evaluate the terms of usability easy to learn. Usability evaluation is multi-dimension evaluation guide which evaluate the usability experience in certain products [3]. However, according to ISO-9241-11, usability evaluation is defined as:

"Extent to which a product can be used by specified users to achieve specified goals with effectiveness, efficiency and satisfaction in a specified context of use"

Usability is focus on 3 criteria such as i. efficiency (Specific prototype software efficiency can be seen in the ability to understand learning using those prototype. Effective evaluation is done by calculating the correct answers answered by consumers), ii. effectiveness (Effectiveness is refer to result of study after certain method of study using prototype is used. Therefore, usability evaluation is done using pre-test and pasca test. If pasca test result is better than pre-test, we can conclude that prototype usabibility is effective) and iii. Satisfaction (Satisfaction is usability evaluation which been evaluated in certain application system. For specific prototype software, satisfaction is refers to prototype characteristic which is easy to use, understandable and attractive. Generally, questionnaire used to evaluate user satisfaction level after prototype testing.). However, criteria evaluation is depends on development research of certain specific 
The International Journal of Multimedia \& Its Applications (IJMA) Vol.6, No.3, June 2014

prototype software. For specific prototype software usability evaluation donne according to user satisfaction criteria.

\section{METHODOLOGY}

ArTerma interface was developed from the combination of model named (A1(DDI)2E3). (A1(DDI)2E3) model is a combination of model and concept model as: i. ADDIE model, ii. 'Diegesis-Spatiality' concept model, iii. 'Frame' concept model and iv. Mental concept model.

ArTerma development is based on ADDIE model because it have 5 main phase as: i. Analysis phase, ii. Design phase, iii. Development phase and iv. Implementation phase and evaluation phase. However, this ADDIE model will during evaluation process in every level of model phase. The ADDIE model is divided into 3 divisions. Those 3 divisions are: i. Pre-cycle process (A1) (see figure 5), ii. Development process cycle ((DDI)2) (see figure 6 and 7), and iii. Post research process cycle (E3) (see figure 8). Besides, in EG interface development conformity factor is important which covers the reaction occurs from early installment till the mind reaction from gamers.

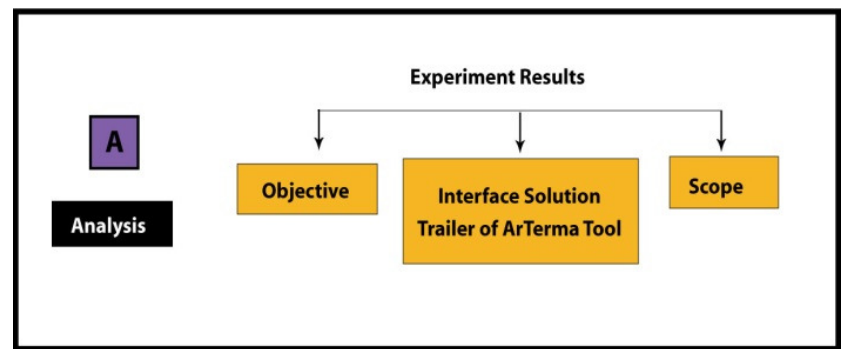

Figure 5: Pre-cycle process (A1). The Analysis Phase of ArTerma research framework

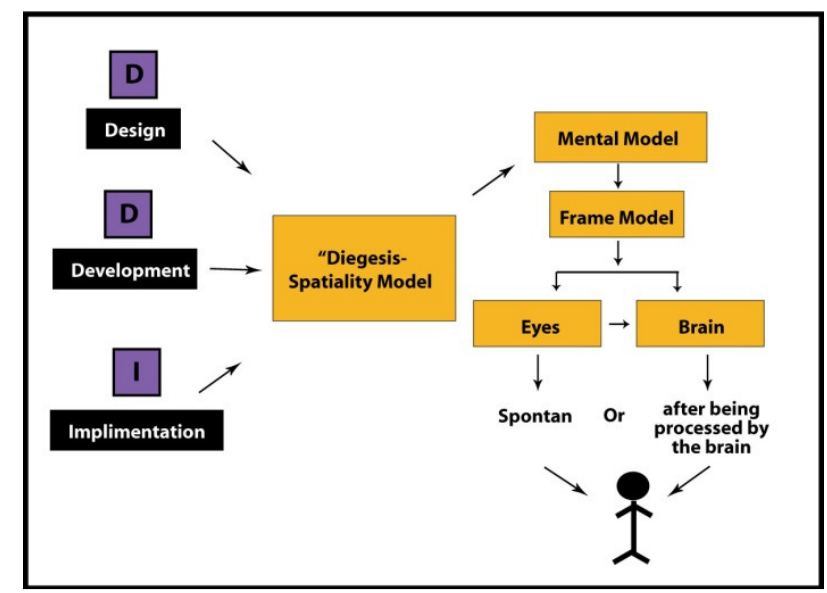

Figure 6: Development process cycle ((DDI)2). The Design, Development and Implimentation Phase of ArTerma research framework 


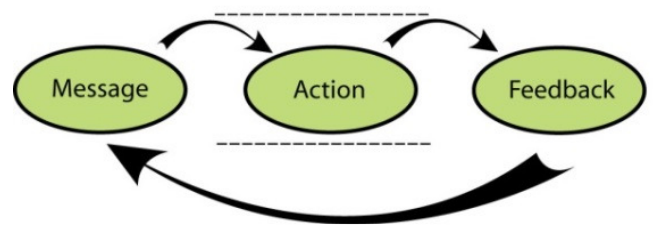

Figure 7: Frame concept model

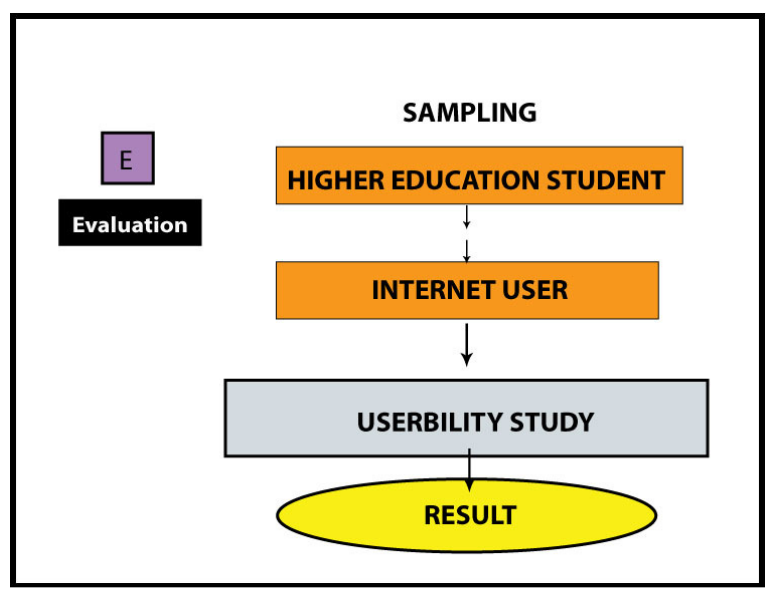

Figure 8: Post Development Process Cycle (E3).

The Evaluation Phase of ArTerma research framework

Process cycle before research include analysis phase. In this phase, all information from the experiment will be analyzed. That information are: i. Research Objective, ii. Research Proposal and iii. Scope of research. However, this research objective: i. to know and analyzed problem in EG interface usage especially POV interface and in war game genre and ii. To create and develop ArTerma in trailer form and the research proposal is to develop POV interface by using tool ArTerma device. Research scope is to focus on High Education Institution (IPT) students and players.

\section{CASe STUdies}

The EG that the study is attempting to develop is a war genre game based upon the war between the Malaysian Armed Forces against the communist guerrilla. The war strategi in this game includes several stages: i) observation ii) arranging the platoon iii) destroying land mines, traps and obstacles iv) targeting major targets v) initiating attacks vi) mission accomplished. The design as well as the process of the project development employ the 3D software studio max because this software is capable of creating character shapes and environments realistically using lighting and texture effects making the outcome very attractive with character view can be seen in $360^{\circ}$ compared to $2 \mathrm{D}$ animation softwares.

The characters are the main attraction of an EG. The main function of a character is to express the genre of the EG through its character, movement and actions parallel to the plots and storyline of the EG. Therefore, the character design needs careful work and can be time consuming [15]. For 
The International Journal of Multimedia \& Its Applications (IJMA) Vol.6, No.3, June 2014

the EG that this research intend to develop, the characters shall be added with Malaysian accessories which can be clearly observed on the character attires which will have stripes as shown in Figure 9 below.

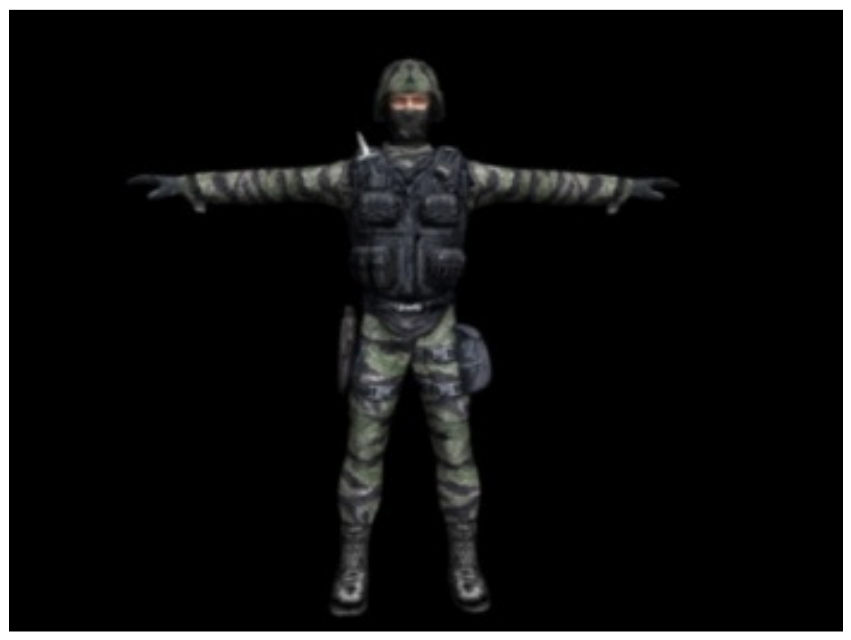

Figure 9. Character using Malaysian war costumes (with stripes).

The language used shall be the Malay language to be consistent with the Malaysian national image. This is also intended to make it easier for users to get into the story and understand the message that the developer is attempting to convey. Indirectly, the EG is intended to attract the Malaysians to understand the Malaysian Armed Forces and know their roles better with the greater goal of instilling patriotism among the players.

The use of equipments as well as the locations which brings out the Malaysian elements is not neglected by the developer. Such elements are: i) Guns, ii) Genade, iii) Bags and other equipments. The background of the warfields is the tropical forests synonymous with Malaysia. Several interfaces has been developed and added with some graphical elements such as: 1) writing 2) audio 3) animation can be clearly observed in Figure 10-12.

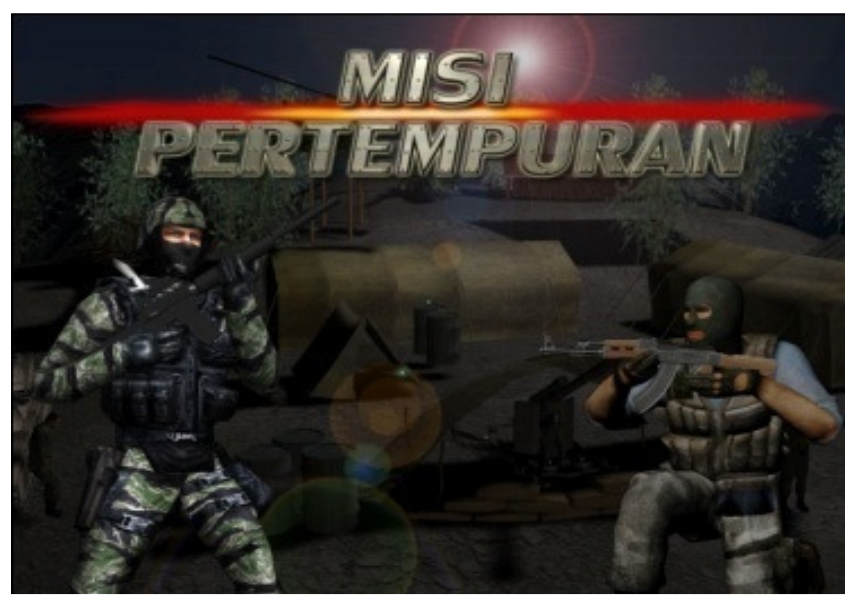

Figure 10. Main Interface of the software 
The International Journal of Multimedia \& Its Applications (IJMA) Vol.6, No.3, June 2014

The main interface of the montage is shown as in Figure 10. The montage is intended to attract users via a simple information medium on the EG storyline and the rules of the game and how the game is to be played. Therefore, the player can move on into stages in the game without losing touch on what they are supposed to do. The interactive Montage that the research is trying to develop includes the 6 elements of the art of drawing which are: 1) points 2) lines 3) shapes 4) textures 5) appearance 6) colour. The development shall 3D studio max in full. The selected colour element is the dark colour or the "low key" colours to enable users to fully experience the darkness of war and the tropics in full. To further add to the war experience, the background music is carefully selected. The background selected is "Derap Komando" sang by the band "Search". The researcher decides that this song is very suitable for war genre games. How ever, the suitability of the song well is confirmed by the target users in the user testing.

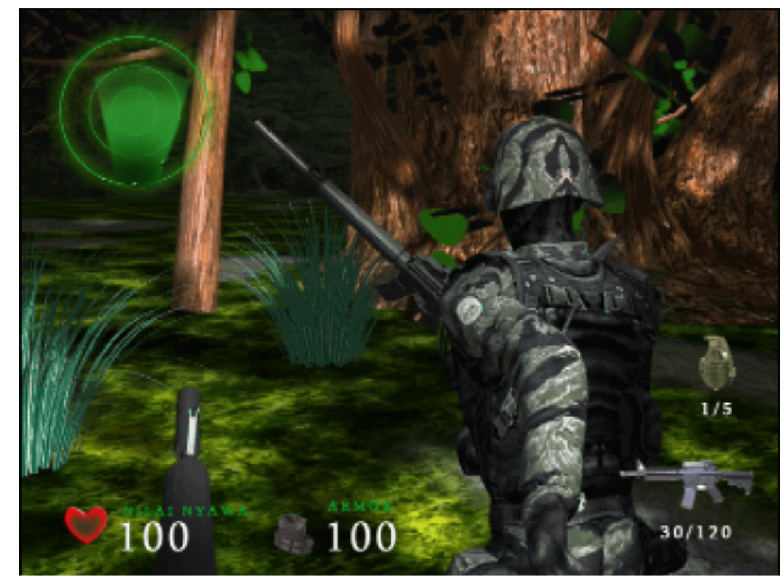

Figure 11. Interface with tools menu

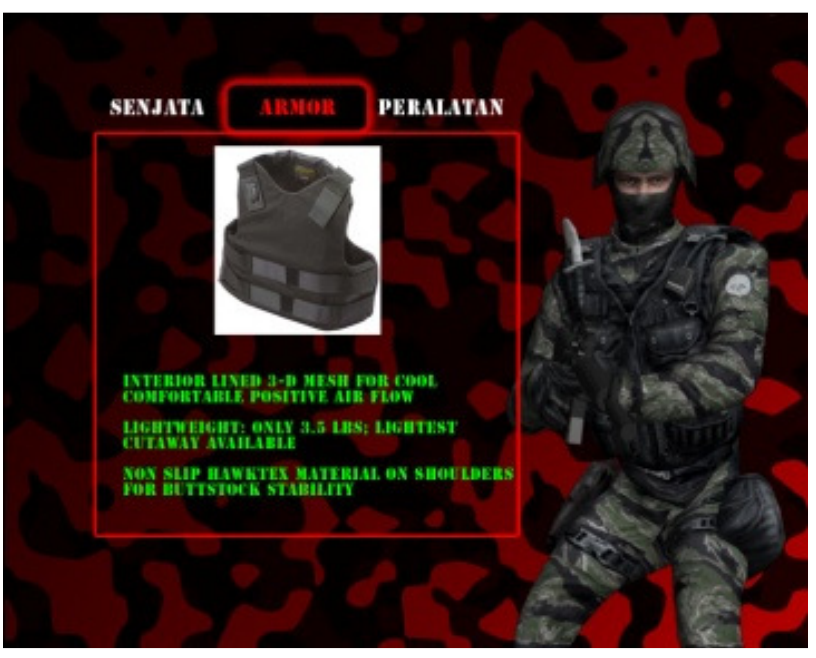

Figure 12. Menu description interface

A support tool known as ArTerma is integrated in the EG consistent with the research objective. The development of this support tool is hoped to be able to make it easier for users to get information on i) player, ii) environment and iii) tool (in figure 11-12). Player information 
The International Journal of Multimedia \& Its Applications (IJMA) Vol.6, No.3, June 2014

includes number if troops and troopers suitable to enemy convoy or specifically the sections, platoons, companies or battalions. Environment information includes the geographical texture of communist camps in 3D, the location of enemy forces (in yellow) and the location of the Malaysian Army Forces (in red). Equipment information includes the name of the weapons or equipments used including the size, weight and the ammunition.[9]

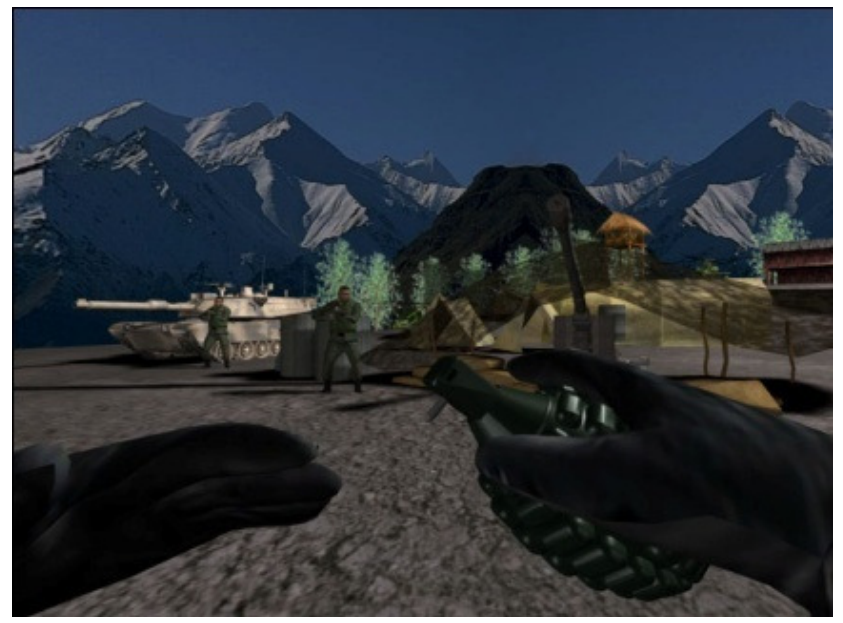

Figure 13. Illustrates the POV usage interface

Lastly, the researcher decides to maintain the use if POV interface in the development of this interactive montage (Figure 13). This is consistent with the objective at the beginning of the project which is to eliminate the problems associated with POV interface.

\section{CONCLUSION}

The fundamental of this project is based on the results of the initial survey which found that POV has its limitations and it is the intention of the research to rectify these problems. The study attempts to overcome the limitations of POV interface using the ArTerma tools which will enable users to play POV games more conveniently. The outcome is that users can better strategize and focus better on the mission objectives. They can also organize platoons and their equipments better using the additional ArTerma tools. This can reduce the problem of games players becoming "somewhat dizzy" as explained earlier in the introduction.

The elements of local environments are quite new and shall present a new challenge on the players. This can, hopefully, inculcate the spirit of nasionalsm into the players expecially for teenagers. Further developments on the ArTerma tools for EG are needed to make them more marketable. Therefore, the study considered some suggestions to get the knowledge from: 1) programming expertise collaboration, 2) graphical arts experts, 3) military servants, and 4) teenagers in EG development. Programming and graphical art skills are undoubtedly very important in developing the software. Programming will be more focussed on the movements of the tools in a software interface. Meanwhile, the military servants can give some insights into the the war strategies employed by the Malaysian Armed forces. The teenagers as the largest group of EG players can give their opinion on what constitutes a good POV game. 5) The use of multilingual instructions and explanations is also sensible considering the multi-ethnicity of 
The International Journal of Multimedia \& Its Applications (IJMA) Vol.6, No.3, June 2014

Malaysians. Should the game be marketed outside Malaysian country, more languages need to be inserted. Among the languages included in the software are English, Chinese and Tamil languages. This can further attract more users to use software with ArTerma interface.

\section{ACKNOWLEDGEMENTS}

Special thanks to Faculti Informatic and Computer (FIK) from Universiti Sultan Zainal Abidin (UniSZA), Universiti Kebangsaan Malaysia (UKM), for my lovely supervisor Azizah Bt Jaafar the senior lecture in FTSM, UKM for her support, advices and commitment to supervice for this researcher.The last one for Irza Shayani Bt Samaden for her support, information and advice that is very helpful.

\section{REFERENCES}

[1] Ahmad Fauzi Mohd Ayub.,(2008).“Pengajaran Dan Pembelajaran Matematik Kalkulus Menggunakan Model Pengajaran Terus dan Model Pembelajaran Masteri : Pakej TEMACCC.” Tesis Dr. Falsafah Teknologi Maklumat. Fakulti Teknologi Dan Sains Maklumat : UKM Bangi, Selangor D. E.

[2] Azizah Jaafar, Halimah Badioze Zaman \& Tengku Mohd Tengku Sembok., (2006). "Penilaian Kepenggunaan Reka Bentuk Interface Perisian Kursus Matematik Sekolah Bestari”. Jurnal Teknologi Maklumat \& Multimedia 3,: 89-106. UKM Bangi, Selangor D. E.

[3] Bleecker, J., (2007)."Vis-a-Vis: A physical user interface for mobile games ( focus point of view in a first person )". Los Angeles: CA .[Internet sources] 2 Januari 2010, from http://notalion.com/documents/honors.pdf.

[4] Carvalho, L., Dong, A., (2010). Bringing a social realist approach into the design of computersupported learning environments: The Design Studio case study. 6th International Basil Bernstein Symposium: Philosophy and sociology of knowledge and its transmission, Brisbane.

[5] Cason II, R ., Larson, E., Robertson, J ., Frisch, J., Trice III,G., and Prayaga, L., (2009). "First Person Shooter Game, Journal Of Object Technology," Vol. 8. No. 1, Online at www.jot.fm., Chair of Software Engineering @JOT, Published by ETH Zurich.

[6] Choi, D. Konik, T., Nejati, N., Park, C. \& Langley, P., (2007).“A Believable Agent for First-Person Perspective Games." American Association for Artificial Intelligence, Internet sources 8 November 2009 from http://logic.stanford.edu/ konik/Research/Papers/2007_AIIDE/aiide07.pdf

[7] Choi, D., Konik, T., Nejati, N., Park ,C \& Langley. P., (2007).“A Believable Agent for First-Person Shooter Games." American Association for Artificial Intelligence, [internet sources] 8 November 2009, from http://www.aaai.org/Papers/AIIDE/2007/AIIDE07-013.pdf.

[8] Courtier, R.,(2008) "Eyes and Mouse: A Study of Multi-Modal Human-Computer Interaction".

[9] Irma Shayana Bt Samaden, Azizah Bt Jaafar., (2012). Kerangka Kerja Pembangunan Montaj Interaktif, Pandangan Orang Pertama (POV) Permainan Elektronik (PE) yang Berkonsepkan Peperangan. Proceedings of the 2nd. International Conference on Arts, Social Sciences \& Technology, Penang, Malaysia.

[10] Jacob, R. J. K., \& Karn, K. S.,( 2003). "Eye Tracking in Human-Computer Interaction and Usability Research: Ready to Deliver the Promises.” In Hyönä, J., Radach, R., \& Deubel, H. (Eds.).The mind's eye: cognitive and applied aspects of eye movement research. Amsterdam: Elzevier .

[11] Jones,S.,"Intelligent User Interfaces.,(1999).” 0657.425/525 Human Computer Interaction. Slaid, t.tp:t.pt.

[12] Kieras, D.,(1994)."GOMS Models for Task Analysis”, [internet source] 19 Nov 2009, from http://ai.eecs.umich.edu/people/kieras/docs/TA_Modeling/GOMSforTA.pdf.

[13] Kumar, M., (2007)“Gaze-Enhanced User Interface Design”,,[internet sources] 20 Jun 2011, from (http://hci.stanford.edu/research/GUIDe/publications/Manu\%20Kumar\%20Dissertation\%20\%20Gaze enhanced\%20User\%20Interface\%20Design.pdf). 
The International Journal of Multimedia \& Its Applications (IJMA) Vol.6, No.3, June 2014

[14] Lankoski ,P., \& Björk, S ., (2007). "Gameplay Design Patterns for Social Networks and Conflicts, [Internet sources] http://www.cse.chalmers.se/research/group/idc/ituniv/kurser/09/idproj/papers/lankoski_bjork_GDTW 2007_FINAL.pdf. )[ 8 Nov. 2009]

[15] Laurie N. T.,(2002)."Video games: Perspective, Point-of View and Immersion.” Tesis sarjana,t.tp: Universiti Florida.

[16] Lee,S.M.,Remington, R., Ravinder, U. \& Matessa, M.(2010)'Developing human performance models using Apex /CPM-GOMS for Agent-based modeling and simulation." Military goverment and aerospace simulation symposium. CA : Moffett Field.

[17] Lin, J.,(2010) "How to Design a Professional Page Layout. “ Thesis Of Bachelor of Science degree in the English Technical Communication \& Media Arts, Southern Polytechnic State University: t.pt

[18] Molenda, M.,(2003)."The ADDIE Model.“A. Kovalchick \& K. Dawson, Ed's, Educational Technology: AnEncyclopedia. Copyright by ABC-Clio, 2003, Santa Barbara : CA.

[19] Saunders .K, Novak .J.,(2007).“Game Development Essentials: Game Interface Design.” 2007.United States: Amerika.

[20] Taylor .L. N. (2002)."Video games: Perspective, Point-Of-View And Immersion”. [internet sources] 11 November 2009 from http://www.purl.fcla.edu/fcla/etd/UFE1000166.

[21] Wan Nurnadiah Wan Mohd Puzi, Faaizah Shahbodin Dan Burairah Hussin,(2010).”Development Of Research Framework for PBL Problem Scenario Using Linear \& Non-Linear Multimedia".Proceedings of regional Confrence on knowledge integration in ICT 2010. Melaka.

[22] Zhai, S.,(2003).”What's in the Eyes for Attentive Input." Communications of the ACM, vol. 46(3): pp. 34-39. 2003,t.tp:t.pt.

[23] Zuraidah Baharin.,(2010)."Perisian Multimedia Pendidikan Sains Komputer Matrikulasi,” 2010. Tesis Sarjana Teknologi Maklumat. Fakulti Teknologi Dan Sains Maklumat : Universiti Kebangsaan Malaysia.

\section{AUTHORS}

Irma Shayana Bt Samaden is a lecturer in University Sultan Zainal Abidin , Terengganu. In 2005, she hold a Digree in Art and Designer (Graphic) from University Technology Mara (UiTM) 2002, In 2003, she hold a Digree in Art and Designer with (Hons)(Graphic) from University Technology Mara (UiTM), and Master Of Information Technology (Information Sciences) from University Kebangsaan Malaysia (UKM), Her researcher interested are Art and Design, Graphic and Human Computer Interaction (HCI).

Azizah Bt Jaafar is the researcher with 14 years experience as academia. She headed a multimedia researcher group during her tenure at Faculty Technology and Information Sciences. Currently, she is with Visual Informatics Institute as Senior Research Fellow. She won several research grants from the government and university to finance all of her projects. She won several research awards (Silver and Gold in 2008 and 2009 International Invention, Innovation Technology Exhibition and 2 Silvers in 2011 Malaysian Technology Expo Competitions. She is also active in several university's community researches and she heads one of the project conducted in West Malaysia, Sabah)

Irza Shayani Bt Samaden is graduated digree from Faculty of medicine, National Medical University O.O Bogomolets Kyiv, Ukraine
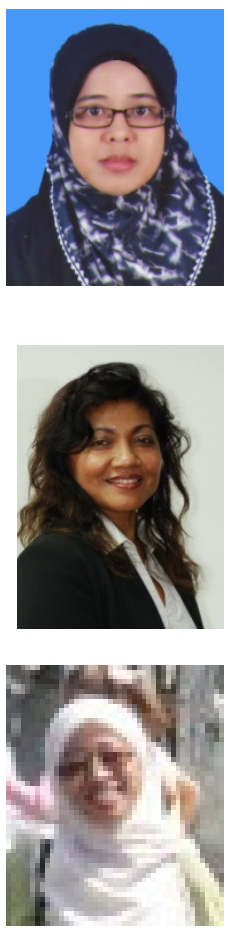